\title{
WHAT EDUCATOR CAPABILITIES ARE NECESSARY FOR REFLECTIVE LEARNING IN ACCOUNTING STUDENTS?
}

\author{
K. Ramsarghey \\ Accounting and Law \\ Mangosuthu University of Technology \\ Durban, South Africa \\ e-mail: kevinr@mut.ac.za / http://orcid.org/0000-0003-3373-6375
}

\section{ABSTRACT}

One of the main roles of universities is to facilitate quality teaching and learning in accordance with applicable professional and academic standards. Academic departments are required to ensure that qualifying teaching staff possess the necessary experience to offer these qualifications. Accounting lecturers in South African universities are employed based mainly on their Accounting qualifications. However, in order to secure tenure in Accounting academia, the prospective lecturer has to satisfy employment criteria for teaching and learning, research and community engagement. An educator's approach to teaching determines whether he/she is teacher-centred or student-centred. This article seeks to determine the relationship between educator capabilities and student performance. In discussing this relationship, it is clear that work/industry experience, teaching qualification and teaching experience are intended to satisfy the aspect of teaching and learning which, in turn, is expected to improve student performance. System Dynamics is used as an analytical model to determine the relationship between lecturer capabilities and student performance. The model is used on the three areas of educator capabilities, namely, work experience, teaching qualification and teaching experience as criteria for improving student performance in Accounting education. In the final analysis, this article argues that lecturers who possess these critical qualities tend to be student-centred, which is necessary for reflective learning in students.

Keywords: student-centred, System Dynamics, teacher-centred, teaching experience, teaching qualification, work experience

\section{INTRODUCTION}

This article undertakes to determine the relationship between educator capabilities and student performance within the context of higher education. According to Lubbe $(2014,122)$, teaching should provoke deep understanding and not mere surface learning. Students that adopt a deep approach to their learning are learners that retain the structure of the task and attempt to relate new knowledge to existing knowledge. These learners are learning to understand therefore they consider evidence presented and conclusions drawn to make informed personal conclusions. They examine logic and arguments critically and are actively interested in the course content. 
Students who adopt a surface approach to learning, in contrast, are often considered to be studying without reflecting and find difficulty in making sense of new ideas and concepts. They employ passive learning techniques such as memorising, note-taking, recognising and relating. One of the deficiencies with the students that adopt a surface approach to learning is that they are learning to obtain a basic understanding of the content. These learners are studying to pass and not necessarily studying to understand. Biggs $(1999,58)$ agrees, stating that deep learning relates to students who learn to understand while surface learning relates to students who learn to pass. This article has three parts dealing with educator capabilities which are work experience, teaching experience and teaching qualifications.

\section{EDUCATOR CAPABILITIES AND STUDENT PERFORMANCE}

Since this article seeks to determine the relationship between educator capabilities and student performance, this focus needs to be explained. Educator capabilities include work experience, teaching experience and teaching qualifications. These attributes of the lecturer have an effect on student performance. Miranda, De Castro Casa Nova, and Cornacchione $(2013,464)$ discuss the relationship between teacher qualification and student performance in Brazil. Teacher qualification encompasses academic qualification (teacher's preparation for research and teaching experience); professional experience (professional practice in the job market); and pedagogical experience (preparation for teaching in university versus teaching qualifications via academic development programmes).

Miranda et al. $(2013,466)$ further discuss the direct and indirect benefits that research offers to the teaching of Accounting. The direct benefit is that research informs those of us who are interested in Accounting and allows us to ask and answer questions. The indirect benefit allows us to inculcate new ideas and defend them rigorously. Thus, without research, professors are at risk of becoming obsolete and teaching outdated irrelevant material. Hence, in this article, there is a strong positive link identified between Accounting research and teaching Accounting. The Accounting research teaching nexus is corroborated by Samkin and Schneider $(2014,8)$; Nieuwoudt and Wilcocks $(2005,54)$ and Parker, Guthrie and Linacre $(2011,7)$.

The growth in student numbers over the years has changed the once homogeneous classrooms into a heterogeneous environment. The homogenous classroom once represented a classroom in South African Higher Education that was predominantly male students. The university student population constituted either black or white students, according to the location of the university. Since 1994, post-apartheid South Africa created access to higher education for all race groups resulting in massification in universities. This resulted in students of all race groups having access to all universities, and both male and female students alike 
were treated equally. This gave rise to a heterogeneous classroom environment. The new generation of students is technologically advanced and demanding on lecturing staff in terms of the support that they require both in and out of the classroom. Ng, Hassan, Nor and Malek $(2017,58)$ discuss that the use of technology in education is affordable and practical, thereby minimising barriers in traditional learning styles. These students are participative with enquiring minds as they want to engage with all forms of technology, and this approach requires the lecturer to be student-centred and facilitate rather than lecture. Thus, lecturers have to be adequately prepared in terms of their work experience, teaching experience and teaching qualification attributes to be able to facilitate lectures that meet the demands of the heterogeneous student population. These teaching skills will, in turn, have an effect on reflective learning and improve the pass rates. Accounting academics are technically competent in their discipline, however, most newly appointed educators lack pedagogical skills. Pedagogical skills, in the context of accounting, is to lecture and discuss; to outline the methodology of the various alternative policies; to analyse and interpret financial information and to aid decision making. Furthermore, the educator is exposed to the millennial student in large class sizes. Thus, induction and staff development programmes are essential in assisting new educators to obtain teaching skills. According to Duta and Rafaila (2014, 523), teacher training builds competence, which grants efficiency, precision and confidence.

\section{SYSTEM DYNAMICS APPROACH}

The purpose of this article is to determine educator capabilities on student performance using the System Dynamics (SD) approach to suggest an analytical model. A system is a working whole, made up of many parts that, when put together, function in an organised way. Betts $(1992,39)$ distinguishes between open and closed systems where an open system is able to import and export energy. He further discusses unitary and pluralistic systems, where unitary systems have a single goal as compared to pluralistic systems that have multiple goals. Betts $(1992,40)$ states that education has been treated as a unitary system whereas it is pluralistic with multiple conflicting goals.

System Dynamics (SD) is the dominant systems approach in the researcher's investigation into the effect of educator capabilities on student performance. SD was founded by Jay W. Forrester and others at the Massachusetts Institute of Technology (MIT) in the 1950s. It is an action research approach to understanding complex systems. According to Reynolds and Holwell $(2010,18)$, it includes internal feedback loops and time delays that impact on the entire system. According to Jackson $(2003,66)$, the theory of SD can be described as a number of variables that exist in a complex system that are causally related in feedback loops that interact 
with themselves. These systemic interrelationships between feedback loops constitute the structure of the system which is the determinant of system behaviour. Feedback loops may be positive (reinforcing) or negative (balancing). The system uses feedback loops and stocks and flows to highlight non-linearity. According to Hirsch, Levine and Miller (2007, 243), stocks represent the accumulation of information over time while flows represent the information processes that change the value of the stocks. A stock-flow diagram (Figure 1) was developed as a model to illustrate the causal loop effect of educator capabilities on student performance.

\section{EDUCATOR CONTENT CAPABILITIES}

Educator capabilities are considered, in this article, as, comprising work experience, teaching qualifications and teaching experience. Work experience relates to the lecturer's industry experience prior to becoming an accounting academic. Mounce, Mauldin and Braun (2004, 399) state that this specialised experience has a positive effect in the classroom and enhances the quality of lectures being facilitated to students. Teaching qualifications relate to qualifications obtained that focus on pedagogical skills and the ability to teach effectively. These qualifications and development programmes train the lecturer to be student-centred and to promote student participation for student success. Teaching experience refers to the time spent as an academic and how that time has improved the academic as an effective lecturer. These academic capabilities will now be discussed in detail.

\section{Work experience}

Accounting academics begin their careers by first completing a primary accounting degree and then proceed to post-graduate qualifications either pursuing the chartered accountant (CA) stream or the honours and master's degrees in accounting. The CA stream follows a rigid path as traineeship is compulsory. The traineeship can be served either in commerce and industry or inside public practice and can vary from anything between three and five years. During the traineeship, the article clerk can write the qualifying board examinations to be registered as a CA and obtain professional membership with the South African Institute of Chartered Accountants (SAICA). Upon completion of the traineeship and the qualifying board examinations, the CA then has the option to choose a permanent career. The popular options, among others, are remaining in practice; working in commerce-related careers; in the investment sector and/or banking; starting up a business; and academia. The CA who opts to become an academic enters a new career path with different values and practices.

The accounting graduate who completes post-graduate qualifications and finds employment in commerce and industry is well remunerated, as accounting is classified as a 
scarce skill. This individual can spend many years gaining experience performing the accounting and internal audit function. The key performance areas (KPAs) could include taxation, management and financial accounting, and auditing. These work areas are linked to the curriculum undertaken in the under- and post-graduate qualifications. This accounting graduate could opt for a career change and seek employment in the Higher Education (HE) sector as an academic.

These potential accounting academics come from different commerce and industry work environments but bring a wealth of knowledge and experience from their past careers. The learning curve during the tenure as trainee accountant or apprentice is extremely steep and this knowledge brings invaluable experience into the classroom when the accountant starts lecturing in higher education. According to a study carried out by Mounce et al. $(2004,406)$, academics possessing practical experience are perceived to be of higher quality than those without practical experience.

Higher Education is currently focused on three pillars, i.e. Teaching and Learning (T\&L), Research, and Community Engagement (CE). According to Tang (1997, 385), these areas are the key missions of university professors. The $26 \mathrm{HE}$ Institutions in South Africa are funded by Government and much attention is placed on research outputs. The Accounting professional bodies such as SAICA prescribe the curriculum of Accounting departments to produce CAs. It is important for the universities to have SAICA accreditation as this attracts students into those universities. The tension between producing CAs and teaching to develop a research culture has placed accounting academics in a difficult space. Van der Merwe, McChlery and Visser (2014, 277) concur that HEIs are pressurised by professional bodies to gain accreditation. Professional associations such as SAICA influence the curriculum, teaching methods and assessments. This practice causes an imbalance between academic and professional epistemologies. The CA qualification is structured to achieve "technical complexity, contextualisation and professional skills but limited conceptual thinking" (Van der Merwe et al. 2014, 279). The accounting qualification limits substantial research work. According to Van der Schyf,

"The university authorities are also applying increasing pressure on Departments of Accounting to engage actively in research and to form part of the research community participating in the search for truthful knowledge that is an essential part of the nature of a university. This is a vital step away from the traditional academic culture of Departments of Accounting." (Van der Schyf 2008, 3).

The research outputs of Accounting academics are generally very low as research is not a 
component of a CA qualification. The CA qualification is pegged at master's level in the universities and hence accounting academics who hold CA qualifications now find themselves in unfamiliar territory where they have to pursue master's and/or doctoral studies with research being the major component of this study.

Grottke, Pelger and Schmiedeberg $(2013,67)$ investigate German-speaking accounting PhD students' career preferences in terms of firm (work experience) or faculty (teaching/lecturing experience). The $\mathrm{PhD}$ students have to choose a career either in academia or business practice. The writers refer to academics as passionate researchers who view research as a vocation. In contrast, practice-related researchers are referred to as applied researchers. Passionate researchers (academics) have to conform to norms in order to be published whereas applied researchers (practitioners) are not bound by these rules or conducts. Grottke, Pelger and Schmiedeberg $(2013,77)$ state that "The paradoxical situation is that the academic freedom is felt by future practitioners, while future academics are restricted to the 'publish-or-perish' mantra prevalent in international accounting research". Academic freedom, in this context, refers to practitioners being allowed to publish their work without restrictions whereas academics are restricted by norms and rules determined by publishers and the higher education sector. Thus, these restrictions have placed limitations on the growth of Accounting $\mathrm{PhD}$ graduates globally. Furthermore, it is financially more rewarding to pursue a career path as an accounting practitioner than to seek tenure as an academic. Currently, the volatile and unsettling work environment at the South African HEIs, with the student protest action, makes it difficult for a prospective academic to choose tenure at the university over business practice. The academic work environment is plagued by student protest action which causes disruptions to the academic calendar. This places immense time constraints on educators to adapt their teaching approaches to complete the syllabus. The academic work environment, thus, becomes stressful and a less desirable choice.

Caldwell and Gedeon $(2016,353)$ review the first conference on international higher education advances in Valencia, Spain. They highlight teaching innovation and authentic learning via knowledge in action, which is prevalent in universities. Higher educators are strengthening links with industry and creating smooth transitions for learners to move from HEIs to industry. Thus, as much as teaching experience and teaching qualifications are essential in HEIs, work experience is just as important from a practical viewpoint. Caldwell and Gedeon $(2016,350)$ state that "Employment readiness and the competences required in graduates was a strong focal point of the conference, with many presenters discussing building educational bridges between the classroom and the workplace". 


\section{Teaching qualifications}

Duta and Rafaila $(2014,522)$ state that teacher training programmes improve the quality of teaching and education in universities. Teacher training is important to eliminate pedagogical difficulties, as most lecturing staff are employed on the basis of their professional subject areas.

Postareff, Lindblom-Ylanne and Nevgi $(2008,29)$ state that in most European countries teaching in higher education does not require a teaching qualification. However, in order to improve the quality of university teaching, pedagogical training (resulting in teaching certificates being issued) has become necessary for university lecturers. These pedagogical training courses will have the impact of changing lecturers' conceptions of teaching and not necessarily their teaching techniques. "Teachers' conceptions of teaching have been shown to affect the way teachers approach their teaching" (Postareff et al. 2008, 30). Thus, teaching qualifications or teaching certificates can enhance or improve the quality of teaching delivered to the student population at higher education institutions.

De Jong et al. $(2013,27)$ discuss the introduction of the University Teaching Qualification (UTQ) in the Netherlands in 2008. Prior to this date, the teaching qualification was not necessarily a requirement to secure tenure at most Dutch universities. One could become a lecturer in these universities if one met the research competences such as publications in peer reviewed journals. In 2008, the Mutual Agreement of University Teaching Qualification was signed by all Dutch research universities. This national agreement gave rise to the teaching qualification in higher education. According to De Jong et al. $(2013,27)$, "the Dutch UTQ is mandatory, but not by law". By 2012, "lecturer quality" was being used as a performance indicator by looking at the percentage of lecturers that have a UTQ. In order to ensure the maintenance of the quality assurance of UTQ standards, the UTQ is audited in terms of the 2008 mutual recognition of the UTQ.

The teaching qualification became mandatory in the Netherlands to improve the quality of teaching and learning in higher education. Due to globalisation and international standards, there is mounting pressure from all corners of the world to improve higher education teaching by implementing the teaching qualification as a mandatory requirement to teach in higher education. Marques $(2013,48)$ discusses what he terms "the third wave", being the mandatory pedagogic qualification of higher education teaching staff at European Union (EU) level. The first wave refers to the Bologna process where the course accreditation process was done at national level. The second wave refers to the course accreditation at European level. The European Commission Report in 2013 made 16 recommendations toward improving the quality of teaching in higher education institutions. Among these recommendations was a call for mandatory training for higher education teaching staff in universities, giving teaching due parity 
with research. Marques $(2013,48)$ further states in Recommendation 4 that "All staff teaching in higher education institutions in 2020 should have received certified pedagogical training. Continuous professional education as teachers should become a requirement for teachers in the higher education sector." Thus, it is glaringly evident that a teaching qualification is becoming important in many countries and in most higher education institutions.

Remmik and Karm $(2012,126)$ concur that teaching qualifications inclusive of pedagogic courses encourage changes and improvements to lecturing styles. This approach may eliminate previous lecturer errors from being perpetuated by novice or new lecturers. Mangosuthu University of Technology (MUT) is fostering relationships with other institutions to create an environment that is conducive for staff to improve their competencies by engaging in teaching qualifications and development programmes. These development programmes may be classified as having a formal, non-formal or informal delivery format. According to Kamaruddin and Ibrahim $(2010,448)$, the formal delivery format refers to structured programmes offered by formal institutions that award a degree or diploma. The non-formal delivery format refers to skills that are offered via workshops, seminars and conferences that may award a certificate. The informal delivery format refers to sharing of knowledge with colleagues and reading of journals.

Duta and Folostina $(2014,3450)$ highlight that the training of university teachers is studied in the field of professional development. Further, they define training as the ability to develop or perfect skills. The continuous training of academics regarding teaching skills and teaching activities is undertaken so that academic staff equip themselves to prepare future professionals. The widening of higher education has changed the landscape of universities. In South Africa, the once small homogeneous classes are now large heterogeneous classes due to widening access to more students. Furthermore, students are technologically advanced in terms of being computer literate and equipped with laptop computers, smartphones and other electronic devices. Hence, lecturers have to be continuously trained to cope with these changes and keep themselves updated, especially in terms of technology that can assist and enhance the student experience in the classroom environment, e.g. the use of smartboards, blackboards, webinars, social media applications that can assist students, and software updates related to the subject being lectured.

Simona $(2015,815)$ discusses teacher training for embedding life skills into vocational teaching in Denmark. The competences highlighted in the Danish education system are literacy, learning to learn, self-management, creativity and innovation, culture, environment, health, social, relations, communication and democracy. In South Africa, the researcher can draw a parallel to MUT here, since MUT is a vocational institution of being both a technikon and a 
university of technology, offering initially only diplomas and subsequently both diplomas and degrees. MUT academic staff have to be competent and proficient in literacy, numeracy, communication, culture, and self-management to assist students that lack in these particular areas. There is an overlap in the competences required by educators in both the universities in order to be proficient in their execution of their teaching and learning duties.

In many HEIs, teaching development has become widespread and compulsory to enhance the quality of student learning through improved conceptions of teaching. Trigwell, Rodriguez and Han $(2012,500)$ established that lecturers who participated in at least a one-year postgraduate certificate in higher education teaching, obtained valuable pedagogical training and increased their student-focused approach to teaching. This graduate certificate "emphasises the crucial role of teacher thinking, and of developing the scholarship of teaching and changing conceptions of teaching in the enhancement of student learning" (Trigwell, Rodriguez and Han $2012,500)$.

\section{Teaching experience}

At South African universities, accounting academics are employed on the strength of their higher degrees, i.e. Honours or Master's degree in accounting. The potential candidates seeking employment at accounting departments had discipline-specific knowledge and accounting work experience. Once employed, these accountants were placed in a classroom environment with minimal induction or pedagogic training. Lewin and Mawoyo $(2014,87)$ state that induction for new academic staff is compulsory if we want to enable student success. According to Hunde and Tacconi $(2014,496)$, one would tend to teach how one was taught previously and possibly perpetuate mistakes. The new accounting academic will learn informally from other colleagues in the department and faculty. This learning curve will continue at workshops and conferences.

Barlow and Antoniou $(2007,70)$ recommend that the induction programme should take into account new lecturers' needs and not simply be on a tick-list. The quality of the induction programme has an impact on the confidence and stress levels of new lecturers (Barlow and Antoniou 2007, 70). Thus, the induction process is vital in terms of the transition into a lecturing position where the lecturer can be confident and have some control over his/her new career. Nicholls $(2005,613)$ states that the induction programmes that aim to improve teaching and learning strategies should take into consideration novice lecturers' pedagogic knowledge and how they develop their theories of teaching, learning and research. Hence, the aim of the induction course is to professionally develop the new lecturers as teachers in order to enhance the teaching quality while maintaining high levels of research activity. An academic department in a university can employ lecturing staff from junior to senior lecturer levels with honours 
degree to doctoral degree respectively, with varying years of teaching experience, depending on the requirements of the vacancy. The induction programme for these academics can be of a generic nature focusing on teaching and learning in order to improve the teaching skills of both the junior and senior lecturers irrespective of their qualifications or work experience. The induction programme should be designed to empower the lecturers to identify their conceptions of and approaches to teaching.

Over a period of time, the accountant will develop a lecturing ethos and believe that this is best practice for achieving reasonable pass rates. Clinebell and Clinebell $(2008,105)$ recommend that the university should teach business executives to teach. Accountants may be excellent at their profession but are not necessarily good teachers or lecturers. These authors imply that it is the responsibility of the universities that employ the accountants as educators to facilitate the transition from accountant to educator. This facilitation may be achieved through induction and pedagogical training programmes. The issue of students being unemployed was always viewed as a national and not a university problem resulting from the economic crisis in SA. The lecturer does not take responsibility for student incompetency as he/she believes that their subject is only one of many being lectured and the problems belong to the students. Thus, the lecturer's teaching portfolio develops over time and many academics believe their long service has turned them into competent academics. Long, Ibrahim and Kowang $(2014,41)$ list lecturer competencies as "knowledge on subject, clarity of presentation, interaction with students, teaching creativity, clarifying learning outcome, class activity and lecture notes". The abovementioned competencies result in the lecturer being classified as competent by colleagues and students

Thus, the role of a university teacher has become increasingly demanding in view of the changing academic profession, heterogeneous student population and stringent research ethos in terms of publishing, presenting papers and vertical studies.

According to Trigwell $(2001,65)$, "good teaching is oriented towards, and is related to, high quality learning". This would mean that competent lecturers tend to be student-focused, aligning their teaching objectives to their students' learning outcomes. With this approach students develop into deep learners who understand what they are learning and are not merely memorising or rote learning. Lecturers that assume the teacher-focused approach by transmitting knowledge to students limit student engagement and participation in the lectures creating an environment conducive for a surface approach to learning or learning to pass. Tigelaar et al. $(2004,254)$ reiterate that the more active and participative the student is, the more student-centred the learning style will be, while transmitting information to students lends itself to an approach that is teacher-centred. 
Kember and Kwan $(2000,489)$ state in their study that "the strong relationship between approaches to teaching and conceptions of teaching has implications for staff and curriculum development in universities". Carnell $(2007,27)$ links conceptions of teaching to either instruction or construction models, where the instruction model is teacher-centred and the construction model is student-centred. In the instruction model, the teacher transmits knowledge and the students are passive recipients of knowledge, whereas in the construction model, students are encouraged to think, collaborate and challenge each other, supported by the teacher. According to Kember $(1997,271)$, teaching conceptions influence teaching approaches which, in turn, impact on student learning approaches and learning outcomes. Although conceptions of teaching can be associated with the quality of student learning, Kember (2009, 2) confirms that most teaching in higher education is didactic or teacher-centred in nature. Lecturing is the most common form of teaching in universities with very little student participation. According to Kember $(1997,255)$ and Kember $(2009,2)$, teachers in higher education who adopt a teacher-centred approach to teaching are labelled as teachercentred/content-oriented as opposed to teachers who adopt a student-centred approach to teaching being labelled as student-centred/learning-oriented. Lecturing persists as a predominant form of teaching in universities because it is difficult to change the deep-seated beliefs of academic staff. Venter and De Villiers $(2013,1254)$ posit that SAICA has colonized the curriculum of 13 SAICA accredited universities in SA (accounting departments). SAICA prescribes technical teaching leaving no room for research and critical thinking. Hence, the teaching for technical expertise versus the teaching for critical thinking places the accounting educator in a quandary, as both the professional bodies and higher education research expectation are equally important.

Akerlind $(2003,375)$ discusses growth and development in a lecturer, as the teacher's comfort with teaching, the teacher's knowledge and skills, and learning outcome for students are the categories that lecturers valued in terms of development. A commonality among studies in teaching strategies indicates that the teacher-centred approach, where transmission of information to students occurs, lends itself to a surface approach to learning or rote learning by students. The student-centred approach to learning, where conceptual understanding occurs, is likely to encourage a deep approach to learning. Akerlind $(2003,376)$ states that the teachercentred focus is "less likely to produce high quality learning outcomes amongst students". Tigelaar et al. $(2004,254)$ and Trigwell $(2001,65)$ concur with this view of a teacher-centred versus student-centred approach to learning. Martin et al. $(2000,389)$ also agree that the student-centred approach results in more effective learning. They discuss "the object of study" that highlights the intentions of the lecturers and what it is that lecturers want their students to 
learn. Martin et al. $(2000,409)$ state that lecturers who accept the objective of study in respect of "knowledge as given" adopt a teacher-focused approach to teaching, while those lecturers that accept the objective of study in respect of "knowledge as being constructed" adopt a student-focused approach to teaching.

In response to teacher-centred and student-centred approaches to teaching and learning, Ramsden et al. $(2007,141)$ advocate a variation in teaching methods, where context-dependent approaches could apply to situations where a university lecturer may transmit information in one context but help students understand difficult concepts in another. Variations in teaching methods are linked to the context of teaching. For example, class size, academic workload, language skills, and prior knowledge of the subject matter are factors that could impact on the way in which educators deliver lectures (Ramsden et al. 2007, 141). From the researcher's experience, if student-centred is on one end of the teaching and learning continuum and teachercentred is on the other, lecturers should be allowed the flexibility to move along the continuum, depending on the context of the teaching (as mentioned above) and the level of difficulty of the concepts being lectured. Variation in teacher competence will determine where a lecturer will place himself/herself on the teaching and learning continuum, that is, "Am I transmitting knowledge or am I supporting teaching and learning for my students?" Trigwell, Prosser, and Waterhouse $(1999,67)$ state that by developing students' conceptions, lecturers change their approach to teaching in a student-focused way and tend to avoid a teacher-focused way that lends itself to a surface approach to learning. Prosser and Trigwell $(1997,51)$ concur that there is a link between the different ways of lecturing (variation in teaching) and the ways students approach their learning.

According to Trigwell $(2012,607)$, "there are significant relations between the way teachers emotionally experience the context of teaching and the ways they approach their teaching, with positive emotions being associated with student-focused teaching approaches and negative emotions with transmission approaches". Lecturers are bound to experience emotions in the work environment due to various encounters such as the culture and politics of the university, the interaction with the students/parents/other colleagues, and participation in statutory meetings with management or with the student representative council. These encounters could invoke either positive or negative emotions in the lecturer that could, in turn, have an impact on the teaching that follows. Positive emotions are triggered by joy, satisfaction, pride, and excitement while negative emotions are triggered by anger, frustration, anxiety, and sadness (Trigwell 2012, 609-610). Positive emotions are motivational whereas negative emotions reduce motivation. Currently, South African higher education institutions are faced with student strikes due to fee protests and staff strikes due to outsourcing of essential services. 
These tensions impact on the emotional state of mind of the lecturer on a daily basis and compromise the quality of the teaching and learning that takes place. Thus, emotions directly affect teaching approaches.

Good lecturers are able to expand knowledge and assist students to understand the concepts in their discipline. Trigwell $(2001,66)$ terms this "pedagogical content knowledge". McAlpine et al. (2009, 263) distinguish between espoused theories and theories-in-use. Espoused theories relate to intellectual understanding about teaching whereas theories-in-use relate to actual teaching practices. Good lecturers will create some form of coherence between espoused theories and theories-in-use and document the evidence. Savaya and Gardner (2012, 145), discuss two types of theory: espoused theory and theory-in-use: "Espoused theory refers to the worldview and the values that people believe guide their behaviours. Theory-in-use refers to the worldview and values reflected in the behaviours that actually drive their actions." As educators in higher education, we need to acknowledge the gaps between our espoused theories and theories-in-use. Our espoused theories (beliefs) relate to the ideal teaching and learning environment with small classes that are well resourced where a student-centred approach is effective. However, our theories-in-use (actions) find educators in teaching and learning environments that are under-resourced with large class sizes that are teacher-centred where knowledge is being transferred and rarely challenged. In many instances, students are learning to pass and adopting a surface approach to learning.

Thus, to conclude on espoused theory and theory-in-use, as academics, our beliefs do not necessarily result in the actions we practice in the classrooms.

\section{ANALYSING EDUCATOR CAPABILITIES}

In System Dynamics, "stocks" represent resources while "flows" are considered to represent changes in variables. The interaction between the stocks and flows are represented in a stockflow diagram that highlights non-linearity.

The following stock-flow diagram highlights the discussion in this article by measuring the effect of educator capabilities on student performance. The educator capabilities are classified as work/industrial experience, teaching/pedagogic experience, and teaching qualifications. When these educator capabilities impact postively on student performance, the student performance increases, which results in higher pass rates being achieved. Higher pass rates increases the number of graduates which, in turn, increases the funding from government. Increased funding allows the university to increase the first year intake of students and improve educator capabilities through development and training programmes. Hence, more capable 


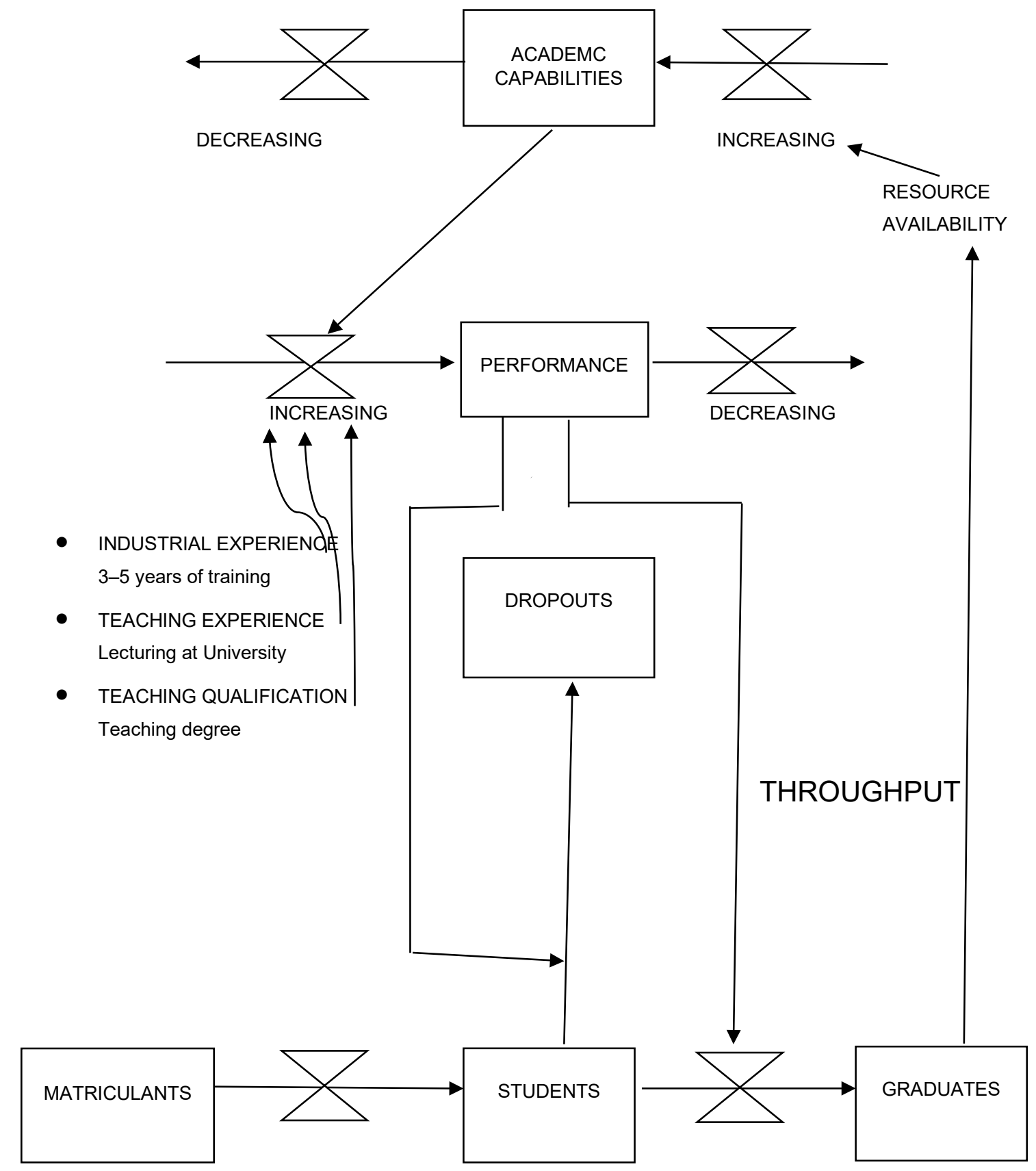

Key:

$\rightarrow \quad=$ flow

$\searrow=$ stock

Figure 1: Stockflow map of educator capabilities for improving student performance (Source: Own observation)

academic staff will deliver improved lectures to new and existing students who will, in turn, excel academically, and the increased student performance will result in increased throughput and graduation rates being achieved by the university. According to Hirsch, Levine and Miller 
$(2007,240)$ systems change involves changing the main cause of a problem through actions to bring about improvement. The diagram illustrates the multiple variables of educator capabilities for improving student performance (dependent variable).

As discussed earlier, the Netherlands has made the teaching qualification mandatory to improve quality teaching and learning in higher education. Marques $(2013,48)$ discusses what he terms "the third wave", being the mandatory pedagogic qualification of higher education teaching staff at European Union (EU) level. Thus, a teaching qualification is becoming compulsory in some countries.

As seen in the System Dynamics model, matriculants enter the higher education system as students. They will pursue a tertiary qualification with two possible outcomes. If successful, the student will qualify and graduate, otherwise the student will dropout. Graduates increase the funding that flows to the university from the Government. A portion of these resources are used to enhance the capabilities of the lecturers via training programmes and further higher qualifications. A teaching qualification is now required by academic staff to secure tenure, as alluded to in the earlier discussions. The additional staff development programmes and teaching qualifications acquired by lecturing staff increase their competencies in the classroom, which in turn impacts on the student performance in terms of improved pass rates and decreased dropout rates. As discussed earlier, De Jong et al. $(2013,27)$ state that many higher education institutions are promoting the teaching qualification and calling it the licence to teach since it enhances the lecturer's pedagogical skills, which has a direct impact on the students. From the "teaching qualifications" section, it is evident that universities from various parts of the world are moving towards making the teaching qualification compulsory for teaching in higher education, with the intention of improving the quality of teaching and learning.

\section{CONCLUSION}

Work experience is an integral component of being considered a competent lecturer. This invaluable experience is brought into the classroom via discussions and practical examples to simplify student understanding of accounting terminology, concepts and complex calculations.

Teaching qualifications have become increasingly more important in universities with some institutions requiring a teaching qualification before offering tenure to prospective academic staff. The teaching qualification enhances the lecturer's pedagogical skills and shifts the mind-set of the lecturer from being teacher-centred to being student-centred. Studentcentred academics tend to engage the students and allow them to actively participate in the classroom, creating an environment for improved reflective learning.

Teaching experience sharpens the abilities of the lecturer to conduct the classes with 
fluidity and be in a position to solve the enquiries of the students with ease and confidence. Teaching experience provides the lecturer with the opportunity to be in control of the classroom environment where he/she can demonstrate his/her knowledge and expertise and thus engage the students in a meaningful manner. Thus, work experience, a teaching qualification and teaching experience will positively affect reflective learning in accounting students.

Furthermore, a focus on the academic development of lecturing staff provides an imperative for improving educator capabilities, which will lead to improved student reflective learning. Educator capabilities of work experience, teaching qualification and teaching experience remain the driving force in improving reflective learning for accounting education.

\section{REFERENCES}

Akerlind, G. S. 2003. Growing and developing as a university teacher-variation in meaning. Studies in Higher Education 28(4): 375-390. doi: 10.1080/0307507032000122242.

Barlow, J. and M. Antoniou. 2007. Room for improvement: The experiences of new lecturers in higher education. Innovations in Education and Teaching International 44(1): 67-77.

Betts, F. 1992. How systems thinking applies to education. Educational Leadership 50(3): 38-41.

Biggs, J. 1999. What the student does: Teaching for enhanced learning. Higher Education: Research and Development 18(1): 57-75.

Caldwell, S. B. and T. D. Gedeon. 2016. Boldly going where no higher educators have gone before: A review of the 1st International Conference on Higher Education Advances, Valencia, Spain. Procedia - Social and Behavioral Sciences 228: 348-355.

Carnell, E. 2007. Conceptions of effective teaching in higher education: Extending the boundaries. Teaching in Higher Education 12(1): 25-40.

Clinebell, S. K. and J. M. Clinebell. 2008. The tension in business education between academic rigor and real-world relevance: The role of executive professors. Academy of Management Learning \& Education 7(1): 99-107.

De Jong, R., J. Mulder, P. Deneer and H. Van Keulen. 2013. Poldering a teaching qualification system in higher education in the Netherlands: A typical Dutch phenomenon. Revista de Docencia Universitaria 11(3): 23-40.

Duta, N. and E. Rafaila. 2014. Training the competences in higher education - a comparative study on the development of relational competencies of university teachers. Procedia - Social and Behavioral Sciences 128: 522-526.

Duta, N. V. and R. Folostina. 2014. Continuous training of university teachers - theoretical approaches and practical implications. Procedia - Social and Behavioural Sciences 116: 3449-3453.

Grottke, M., C. Pelger and C. Schmiedeberg. 2013. Firm or faculty? Evidence on characteristics of German-speaking accounting $\mathrm{PhD}$ students and their career preferences. Accounting Education 22(1): 66-84.

Hirsch, G. B., R. Levine and R. L. Miller. 2007. Using system dynamics modeling to understand the impact of social change initiatives. American Journal of Community Psychology 39(3-4): 239253. doi: 10.7007/s10464-007-9114-3.

Hunde, A. B. and G. Tacconi. 2014. Teacher educators' practices from the view of building lifelong learning capabilities in student teachers. Procedia - Social and Behavioral Sciences 136: 496500.

Jackson, M. C. 2003. Systems thinking: Creative holism for managers. Chichester, West Sussex: John 
Wiley.

Kamaruddin, W. N. W. and M. S. Ibrahim. 2010. Enhancing Malaysian Polytechnic technical lecturers' competency through the identification of professional development programs. Procedia - Social and Behavioural Sciences 7(C): 446-454.

Kember, D. 1997. A reconceptualisation of the research into university academics' conceptions of teaching. Learning and Instruction 7(3): 255-275.

Kember, D. 2009. Promoting student-centred forms of learning across an entire university. Higher Education 58: 1-13.

Kember, D. and K. Kwan. 2000. Lecturers' approaches to teaching and their relationship to conceptions of good teaching. Instructional Science 28: 469-490.

Lewin, T. and M. Mawoyo. 2014. Student access and success: Issues and interventions in South African universities. Cape Town: Inyathelo: The SA Institute for Advancement.

Long, C. S., Z. Ibrahim and T. O. Kowang. 2014. An analysis on the relationship between lecturers' competencies and student' satisfaction. International Education Studies 7(1): 37-46. doi: 10.5539/ies.v7n1p37.

Lubbe, I. 2014. Educating professionals: Describing the knowledge agency of accounting academics. Meditari Accountancy Research 22(1): 107-127.

Marques, J. C. 2013. Pedagogic qualification of higher education teaching staff - the third wave. International Journal of Engineering Pedagogy 3(4): 47-49.

Martin, E., M. Prosser, K. Trigwell, P. Ramsden and J. Benjamin. 2000. What university teachers teach and how they teach it. Instructional Science 28: 387-412.

McAlpine, L., C. Amundsen, M. Clement and G. Light. 2009. Rethinking our underlying assumptions about what we do and why we do it: Academic development as a case. Studies in Continuing Education 31(3): 261-280. doi: 10.1080/01580370903271461.

Miranda, G. J., S. P. De Castro Casa Nova and E. B. Cornacchione. 2013. To Sir with love: The relations between teacher qualification and student performance in accounting. Review of Business Management 15(48): 462-480.

Mounce, P. H., D. S. Mauldin and R. L. Braun. 2004. The importance of relevant practical experience among accounting faculty: An empirical analysis of students' perceptions. Issues in Accounting Education 19(4): 399-411.

Ng, S. F., N. S. I. C. Hassan, N. H. M. Nor and N. A. A. Malek. 2017. The relationship between smartphone use and academic performance: A case of students in a Malaysian tertiary institution. Malaysian Online Journal of Educational Technology 5(4): 58-70.

Nicholls, G. 2005. New lecturers' constructions of learning, teaching and research in higher education. Studies in Higher Education 30(5): 611-625.

Nieuwoudt, M. J. and J. S. Wilcocks. 2005. The attitudes and perceptions of South African accounting academics about research. Meditari Accountancy Research 13(2): 49-66.

Parker, L. D., J. Guthrie and S. Linacre. 2011. The relationship between academic accounting research and professional practice. Accounting, Auditing \& Accountability Journal 24(1): 5-14.

Postareff, L., S. Lindblom-Ylanne and A. Nevgi. 2008. A follow-up study of the effect of pedagogical training on teaching in higher education. Higher Education 56: 29-43.

Prosser, M. and K. Trigwell. 1997. Using phenomenography in the design of programs for teachers in higher education. Higher Education Research and Development 16(1): 41-54.

Ramsden, P., M. Prosser, K. Trigwell and E. Martin. 2007. University teachers' experiences of academic leadership and their approaches to teaching. Learning and Instruction 17: 140-155.

Remmik, M. and M. Karm. 2012. Novice university teachers' professional learning: To follow traditions or change them? Studies for the Learning Society 2(3): 121-131.

Reynolds, M. and S. Holwell. 2010. Systems approaches to managing change: A practical guide.: 
Springer London

Samkin, G. and A. Schneider. 2014. The accounting academic. Meditari Accountancy Research 22(1): $2-19$.

Savaya, R. and F. Gardner. 2012. Critical reflection to identify gaps between espoused theory and theory-in-use. Social Work 57(2): 145-154.

Simona, G. 2015. Teacher training for embedding life skills into vocational teaching Procedia-Social and Behavioral Sciences 180: 814-819.

Tang, T. L. 1997. Teaching evaluation at a public institution of higher education: Factors related to the overall teaching effectiveness. Public Personnel Management 26(3): 379-389.

Tigelaar, D. E. H., D. H. J. M. Dolmans, I. H. A. P. Wolfhagen and C. P. M. Van Der Vleuten. 2004. The development and validation of a framework for teaching competencies in higher education. Higher Education 48: 253-268.

Trigwell, K. 2001. Judging university teaching. International Journal for Academic Development 6(1): 65-73. doi: 10.1080/13601440110033698.

Trigwell, K. 2012. Relations between teachers' emotions in teaching and their approaches to teaching in higher education. Instructional Science 40: 607-621.

Trigwell, K., M. Prosser and F. Waterhouse. 1999. Relations between teachers' approaches to teaching and students' approaches to learning. Higher Education 37: 57-70.

Trigwell, K., K. C. Rodriguez and F. Han. 2012. Assessing the impact of a university teaching development programme. Assessment \& Evaluation in Higher Education 37(4): 499-511.

Van der Merwe, N., S. McChlery and S. S. Visser. 2014. Balancing academic and professional pedagogies: A comparative study of two accounting departments in South Africa and the UK. Teaching in Higher Education 19(3): 276-288.

Van der Schyf, D. B. 2008. Five recent developments' impact on the traditional academic culture of Departments of Accounting at South African universities. Meditari Accountancy Research 16(2): $1-12$.

Venter, E. R. and C. De Villiers. 2013. The accounting profession's influence on academe: South African evidence. Accounting, Auditing and Accountability Journal 26(8): 1246-1278. 